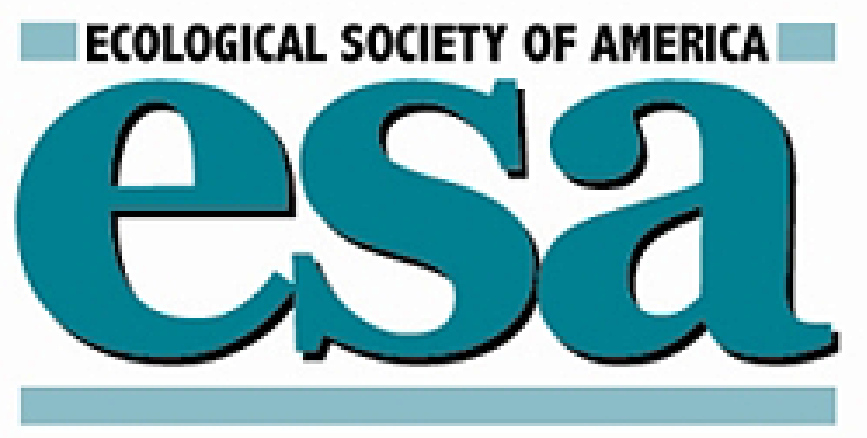

The Ecophysiological Significance of Leaf Movements in Rhododendron Maximum Author(s): Yijia Boa and Erik T. Nilsen

Source: Ecology, Vol. 69, No. 5 (Oct., 1988), pp. 1578-1587

Published by: Ecological Society of America

Stable URL: http://www.jstor.org/stable/1941655

Accessed: 12/03/2014 14:44

Your use of the JSTOR archive indicates your acceptance of the Terms \& Conditions of Use, available at http://www.jstor.org/page/info/about/policies/terms.jsp

JSTOR is a not-for-profit service that helps scholars, researchers, and students discover, use, and build upon a wide range of content in a trusted digital archive. We use information technology and tools to increase productivity and facilitate new forms of scholarship. For more information about JSTOR, please contact support@jstor.org. 
Copyright by the Ecological Society of America. Yijia Boa and Erik T. Nilsen 1988. The Ecophysiological

Significance of Leaf Movements in Rhododendron Maximum. Ecology 69:1578-1587. http://

dx.doi.org/10.2307/1941655

Ecology, 69(5), 1988, pp. 1578-1587

(C) 1988 by the Ecological Society of America

\title{
THE ECOPHYSIOLOGICAL SIGNIFICANCE OF LEAF MOVEMENTS IN RHODODENDRON MAXIMUM ${ }^{1}$
}

\author{
YiJIA BAO AND ERIK T. NILSEN ${ }^{2}$ \\ Biology Department, Virginia Polytechnic Institute and State University, \\ Blacksburg, Virginia 24061 USA
}

\begin{abstract}
The patterns of leaf movements and their environmental stimuli have been documented for over a century. Although there have been several studies on the physiological significance of heliotropisms, thermotropic movements have been largely ignored. The objective of this study was to evaluate the ecophysiological significance of thermotropic leaf movements in a subcanopy plant through controlled experiments. Rhododendron maximum L. was selected because of its strong winter season, thermotropic leaf movements, and the ease of identifying even-aged leaf cohorts. A series of leaf manipulations was established to restrict curling, changes in leaf angle, or both. The effects of these treatments on leaf energy budget, chlorophyll content, photosynthesis, and leaf survival were evaluated.

Leaves that were maintained in a horizontal position (whether they were allowed to curl or not) had the greatest decrease in chlorophyll content and the most inhibited photosynthetic rate. Reduced photosynthetic potential was due to both lower quantum yield and lower light-saturated photosynthetic rates. Optimal temperature for photosynthesis was several degrees above air temperature, corresponding to a horizontal leaf temperature in a sunfleck. Leaf angle influenced leaf temperature during daylight and night time; but the influence was small and most likely had no ecophysiological significance. Leaf curling had little to no influence on the ecophysiological parameters measured in this study.
\end{abstract}

Key words: Appalachian mountains; chlorophyll; energy budget; leaf angle; leaf curling; leaf temperature; quantum yield; Rhododendron maximum; thermotropic leaf movements.

\section{INTRODUCTION}

Since Darwin's work on the patterns of leaf movements (Darwin 1885) environmental stimuli for leaf movements have been extensively studied. Leaf movements can be classified into several groups according to the major effective environmental factor. For instance, nyctitropic leaves respond to darkness, and heliotropic movements are determined by the direction of light. Leaves of diaheliotropic plants (solar-tracking plants) track the movement of the sun to receive as much solar radiation as possible. On the other hand, leaves of paraheliotropic plants move to minimize the absorption of light during the middle of the day. Leaf movements are also caused by temperature (thermotropic) and moisture (hygrotropic).

Although many patterns of leaf movement have been well documented, the ecological significance of leaf movement has been studied in only a few cases. For example, heliotropism and paraheliotropism, usually found in high-irradiance environments, have been related to energy balance and photosynthesis (Forseth and Ehleringer 1983). On the other hand, nyctitropic and thigmotropic movements may conserve leaf nutrients (Wallace et al. 1987) and reduce herbivory in association with thorns. Thermotropism is one of the

\footnotetext{
${ }^{1}$ Manuscript received 8 July, 1987; revised and accepted 15 February 1988.

${ }^{2}$ Address reprint requests to E. T. Nilsen.
}

least understood patterns of leaf movement; however, it has been suggested that these movements may prevent leaf freezing and/or leaf desiccation during winter months (Fukuda 1933, Havis 1964).

Thermotropic leaf movements in Rhododendron species occur throughout the distribution of Rhododendron, and they have been measured in the southwestern and eastern United States (Havis 1964, Nilsen 1985) and in Asia (Fukuda 1933). Recent studies (Nilsen 1985) reveal that leaf curling and changes in leaf angle are related to several external and internal factors. For instance, leaves of $R$. maximum start curling and drooping when leaf temperature is below $-1^{\circ} \mathrm{C}$. Experiments under field and laboratory conditions also show that as leaf water potential decreases, leaf curling and drooping increase (Nilsen 1987). In addition, field evidence indicates that leaf angle is partially related to irradiance.

Several hypotheses have been suggested to explain the significance of leaf movements in Rhododendron. First, leaf curling may serve to avoid drought resulting from low temperature in the winter (Havis 1964). High leaf water deficit in late winter, when the soil in the root zone is frozen, may cause desiccation injury to $R$. catawbiense leaves (Havis 1964). Leaf curling may prevent water loss during the winter by creating a moist microclimate around the stomata or by preventing the stomata from opening (Fukuda 1933, Havis 1964). This interpretation is confounded because leaf temperature and leaf water potential are correlated (Nilsen 1987). 
In addition, temperature-controlled laboratory experiments reveal that low leaf water potential is only partially responsible for leaf curling in the field (Nilsen 1987).

Leaf orientation of Rhododendron species could also be important to the energy environment of the leaves (Mooney et al. 1977, McMillien and McClendon 1979, Gates 1980, Forseth and Ehleringer 1982, Geller and Smith 1982) because of the influence of leaf energyexchange characteristics on plant physiological function or plant survival (Gates 1968, Baskin and Baskin 1978). Leaf temperature can become as much as $15^{\circ}$ above air temperature (Gates 1963, Regehr and Bazzag 1976 ) or $15^{\circ}$ below air temperature (Smith 1978) depending on environmental and leaf conditions. The leaves of $R$. maximum are large, entire, and thick. As a result they have a thick boundary layer and poor convective heat transfer (Parkhurst et al. 1968). Also, during the winter and early spring, transpiration is inhibited because stomata are closed; therefore, latent heat exchange is minimal (Nobel 1983). Horizontal leaves, exposed to a relatively open sky during the winter under a deciduous canopy, may lose more infrared energy at night and receive more total energy at midday than vertical leaves. The horizontal leaves cannot effectively release the absorbed energy through conduction, convection, or latent heat exchange. Consequently, the temperature of horizontal leaves is likely to rise above air temperature during the day and drop below air temperature at night. For example, based on leaf energy-balance equations (Nobel 1983) a horizontal $R$. maximum leaf at $0^{\circ}$ air temperature and $-23^{\circ}$ sky temperature has a leaf temperature of $-6^{\circ}$ (the leaf freezing point); while a vertical leaf under the same conditions has a leaf temperature similar to air temperature (E. T. Nilsen, personal observation). Studies on the interaction of leaf orientation and leaf seasonal or temporal energy budget have been carried out in many desert plants (Mooney and Ehleringer 1978), but not in temperate subcanopy plants, such as Rhododendron in the winter.

Leaf movements may protect leaves from photoinhibition and photooxidation, particularly under conditions of high irradiance and cold temperature (Powles 1984). High light intensities may damage the photosynthetic apparatus, or cause photoinhibition of shade plants because of the imbalance between the quantity of light absorbed and the photochemical capacity of plants (Long et al. 1983). In addition, experiments have shown that the photosynthetic apparatus of leaves is more sensitive to damage by high light intensity (photoinhibition) at low temperature (Ogren and Öquist 1984, Powles 1984, Strand and Öquist 1985).

Few studies have focused on the adaptive significance of leaf movements of a subcanopy species in a seasonally cold environment. Furthermore, to our knowledge, these questions have not been investigated experimentally under controlled conditions. As a re- sult, the basic ecophysiological data necessary to evaluate the potential significances of thermotropic leaf movements in Rhododendron are not available.

The objective in this study was to determine the ecophysiological significance of thermotropic leaf movements in $R$. maximum. Does the significance of leaf movements relate primarily to energy balance, or are other factors such as desiccation, photoinhibition, photooxidation, and water-use efficiency involved? We began our study with the following possible explanations. (1) Leaf movements result in a favorable energy balance of leaves. Thus, without leaf movement, leaf temperature would drop below air temperature during cold nights, or leaves would overheat during a clear midday in winter. (2) Leaf movements are necessary to avoid permanent photoinhibition of the photosynthetic apparatus in chloroplasts during the winter when irradiance is high and leaf temperature is low. (3) Leaf movements are necessary to avoid the permanent photooxidation of chlorophyll. The approach we used to evaluate these possibilities was to establish a series of leaf manipulation treatments, which forced leaves to maintain specific orientations with or without leaf curling. We investigated these possible explanations by determining the influence of leaf treatments on leaf longevity, energy budget, gas-exchange characteristics, and chlorophyll contents.

\section{Materials AND Methods \\ Species and sited description}

R. maximum is a subcanopy evergreen shrub that is distributed in the Appalachian mountain region from Georgia into Canada; $R$. maximum populations reach their greatest dominance in the Appalachian Mountains of Virginia and West Virginia, United States. Leaf size of $R$. maximum ranges from 20 to $200 \mathrm{~cm}^{2}$ with an average of $80 \mathrm{~cm}^{2}$ for mature leaves. Six to ten annual leaves are located in a tight leaf whorl with a long internodal section of stem. New leaf expansion and shoot elongation occur over a short period of time, 1-2 wk, in the middle of May (Nilsen 1985); thus, leaf age within a cohort of whorls is uniform. $R$. maximum leaves survive from 3 to $7 \mathrm{yr}$ depending on the microclimate (Nilsen 1986). The ease of determining leaf age makes it possible to establish treatments within an even-aged cohort, thereby eliminating variation due to leaf age. Leaves are thick, making them resistant to mechanical and insect damage.

The research site was located in a valley of the Jefferson National Forest near Blacksburg, Virginia $\left(80^{\circ} 22^{\prime} 59 \mathrm{~W}, 37^{\circ} 15^{\prime} 47 \mathrm{~N}\right)$, and had a slope of $0^{\circ}$ and an elevation of $640 \mathrm{~m}$. The canopy was dominated by deciduous species (Quercus alba and Acer rubrum). $R$. maximum was the dominant subcanopy species. A more complete vegetation and site description is available elsewhere (Nilsen 1985). 


\section{Leaf manipulations}

In August 1985, six different leaf manipulations were established on in situ leaves in the natural population to examine the effects of leaf curling and leaf angle on leaf energy budgets and photosynthesis.

1) CONT leaves. Control leaves, the leaf curling and angle were not restrained. However, the wire frame and string were attached and holes were punched as in the other treatments.

2) $V C$ leaves. The leaves were restrained in a vertical position, but they were allowed to curl.

3) $V F$ leaves. The leaves were restrained in a vertical position, and they were not allowed to curl.

4) FF leaves. The leaves were free to change angles, but they were not allowed to curl.

5) $H C$ leaves. The leaves were restrained in a horizontal position, and they were allowed to curl.

6) $H F$ leaves. The leaves were restrained in a horizontal position, and they were not allowed to curl.

In addition, unmanipulated leaves of similar age and position were selected, and no treatment or frame was attached.

Several precautions were taken in order to limit the variation among leaves. Only leaves of the same age and free from any obvious insect damage were used. Sample leaves were selected from healthy-appearing branches in the canopy of three $R$. maximum individuals growing near each other. Each treatment included 175 leaves; among them 100 leaves were $1 \mathrm{yr}$ old and 75 were 2 yr old. The six manipulations totaled 1050 experimental leaves.

On each leaf two holes were punched in the middle of the blade on each side of the main vein. The holes were used to support a frame made of thin, insulated wire and a piece of thread. The wire frame was used to prevent the leaf from curling; and the thread was used to restrain the leaf at a specific angle. One each control leaf two holes were punched and a frame was attached by the thread without restricting leaf movement or leaf curling. The six different treatments were assigned respectively to six leaves in each evenaged whorl on each branch.

\section{Ecophysiological measurements}

Just after the leaf treatments were established, on 25 September 1985, a diurnal cycle of leaf temperature, stomatal conductance, and light intensity was measured with a steady-state porometer (LI-COR, Model LI-1600). Air and leaf temperatures were measured with $0.127-\mathrm{mm}$ (36-gauge) copper-constantan thermocouples inserted into the lower side of the leaves. Leaf water potential was determined with a pressure chamber (PMS Instruments, Model 1000).

Observations of visible changes in sample leaves, such as chlorosis or abscission were made during the entire experimental period. These data were collected to determine the influence of the treatments on leaf mortality.

Diel cycles of sample leaf temperatures and air temperatures were measured with thermocouples and recorded with a microdatalogger (Campbell, Model CR21) to determine the consequence of leaf movements on the leaf energy budget. Thermocouples were embedded into the lower surface of the leaf, and temperature data were collected at 5-min intervals from 10-17 February 1986 and from 10-20 April 1986 on two sets of the six manipulations (two leaf whorls, each with six manipulation treatments).

Leaf chlorophyll (chl) content was determined with a UV-VIS spectrophotometer (Gilford; model, Response) on 14 January, 25 February, 27 March, and 15 May 1986. Each time, 16 branches were collected, so that each treatment had 16 sample leaves. Ten leaf disks were punched along the length of both sides of each leaf. The chlorophyll was extracted by grinding the leaf disks of known area in $80 \%$ acetone. The homogenates were centrifuged at $100 \mathrm{~g}$ for $5 \mathrm{~min}$. Absorbances of the supernate were measured at 664 and $647 \mathrm{~nm}$. From the absorbances, $\operatorname{chl} a, \operatorname{chl} b$, total chl (chl $a+\operatorname{chl} b$ ), and chl $a / b$ were calculated (Jeffrey and Humphry 1975).

Gas-exchange measurements were conducted with a null-balance, gas-exchange system (Data Design Group, Model PACsys 9900), using the general design of Field et al. (1982a), in the spring and summer of 1986 . This is a complete, computer-based portable system for making automated gas-exchange measurements on plant leaves in both the field and the laboratory. The system uses two microcomputers for control and display applications. The control/data acquisition computer is housed in the main system unit, together with the integral data acquisition system, mass flow controller (Tylan Corporation, FC260 series), and infrared gas analyzer (Liston Edwards, Incorporated; 1985 model). The control system communicates with the console computer (Tandy Corporation, Radio Shack Model 100). The console accepts data from the control computer, processes the basic data, and displays the data in both tabular and graphical form on the console screen. During the measurements, a single attached leaf was inserted into the cuvette. The temperature, moisture, and $\mathrm{CO}_{2}$ content were controlled in the cuvette. A mass-balance approach was used to budget fluxes into and out of the leaf cuvette. Gases from three cylinders, two containing $\mathrm{CO}_{2}$ at concentrations of 3000 and $320 \mu \mathrm{mol} / \mathrm{mol}$ and one with pure $\mathrm{N}_{2}\left(\mathrm{CO}_{2}\right.$-free air), were used to regulate the humidity and $\mathrm{CO}_{2}$ level in the cuvette. The fluxes were determined using a steady-state "null-balance" approach in which dry air and carbon dioxide were precisely metered into the cuvette at rates that just compensated transpiration and net carbon dioxide exchange, thus maintaining constant cuvette humidity and carbon dioxide concen- 
tration. Leaf temperature was measured with a 0.127 $\mathrm{mm}$ (36-gauge) copper-constantan thermocouple inserted into the leaf lower surface. Leaf temperature was automatically controlled inside the cuvette by Peltier cooling fins. Light was provided by a Sylvania capsylite flood lamp with an appropriate housing, heat filler, and neutral-density light filters. The light intensities were controlled by changing the number of neutral-density filters. Light intensities on the leaves were measured with a quantum sensor (LI-COR, Model 190s). Photosynthesis, leaf conductance, transpiration, and internal $\mathrm{CO}_{2}$ concentration were calculated (Field et al. $1982 b$ ).

Curves of photosynthetic response to temperature were obtained by starting photosynthetic measurements at a leaf temperature of $25^{\circ} \mathrm{C}$, then decreasing the leaf temperature in steps to $18^{\circ}$. The temperature was then increased in $5^{\circ}-7^{\circ}$ steps until $42^{\circ}$ was reached. The optimal temperature obtained was used in all light response measurements.

Similarly, in the photosynthetic-light responses, leaves were first exposed to light at a photon flux density of $270 \mu \mathrm{mol} \cdot \mathrm{m}^{-2} \cdot \mathrm{s}^{-1}(400-700 \mathrm{~nm})$. After a constant photosynthetic rate had been obtained, the light was lowered to total darkness and photon influx was increased in steps of $20-50 \mu \mathrm{mol} \cdot \mathrm{m}^{-2} \cdot \mathrm{s}^{-1}$ until 600 $\mu \mathrm{mol} \cdot \mathrm{m}^{-2} \cdot \mathrm{s}^{-1}(400-700 \mathrm{~nm})$ had been reached. At each step a constant photosynthetic rate was attained before advancing to the next higher light level. Leaf temperature was maintained at the optimal condition, $30^{\circ}$, and vapor pressure deficit (VPD) levels were kept at $<1.0 \mathrm{kPa}$. Ambient (air in cuvette) $\mathrm{CO}_{2}$ levels were maintained at $350 \mu \mathrm{mol} / \mathrm{mol}$.

\section{RESULTS}

\section{Energy relationships}

The results of measurements conducted on 25 September 1985, just after leaf treatments had been established, showed that there were no significant differences ( $t$ test, 95\% confidence level; SAS 1982) in leaf conductance, leaf temperature, and leaf transpiration among treatments; therefore, readings were averaged among treatments. Leaf conductance and transpiration of both control and treated groups were low in the early morning, reached a peak at noon, then decreased slowly (Fig. 1A, B). There were also no significant differences ( $t$ test, 95\% confidence level) in leaf water potential among the treatment groups. Leaf water potential was high in the early morning, reached a minimum at 1400 , then increased again (Fig. 1B). Light intensities on the surfaces of leaves were different among the treatments, i.e., horizontal $>$ control $>$ vertical leaves at midday (Fig. 1C). The maximum irradiance in the summer was $68 \mu \mathrm{mol} \cdot \mathrm{m}^{-2} \cdot \mathrm{s}^{-1}$, which was low in comparison with winter irradiance $\left(180 \mu \mathrm{mol} \cdot \mathrm{m}^{-2} \cdot \mathrm{s}^{-1}\right.$ for horizontal groups), because of light interference by the canopy of

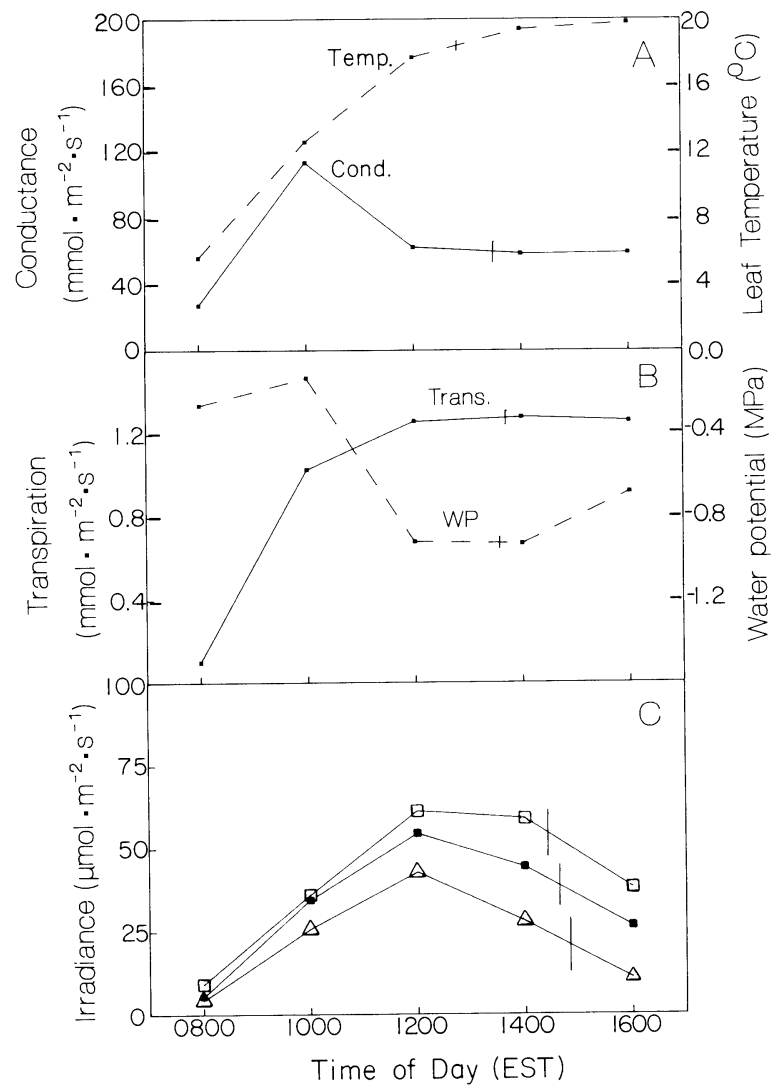

Fig. 1. Diurnal course performed on 25 September 1985 with in situ leaves of Rhododendron maximum. (A) Average leaf conductance, average leaf temperature. (B) Average transpiration, average leaf water potential. (C) Average irradiance on the leaf surface ( $\mathbf{c}$ control leaves; $\Delta$ vertical leaves; $\square$ horizontal leaves). Sample size was 24 , with four leaves in each of six manipulations. Error bars represent two standard errors of the mean. EST = Eastern Standard Time.

deciduous trees. Leaf temperatures among the treatments were not significantly different (difference $<1^{\circ} \mathrm{C}$ ).

During the winter and early spring, before the deciduous canopy trees produced leaves, the light environment was quite different among the treatments. For example, measurements made at midday of 30 March 1984 (E. $\mathrm{T}$. Nilsen, personal observation) revealed that the light intensity on horizontal leaves $\left(180 \mu \mathrm{mol} \cdot \mathrm{m}^{-2} \cdot \mathrm{s}^{-1}\right)$ was significantly higher ( $t$ test, $95 \%$ confidence level) than that of more vertical leaves $\left(90 \mu \mathrm{mol} \cdot \mathrm{m}^{-2} \cdot \mathrm{s}^{-1}\right)$.

Because diel temperature patterns were variable among the days measured, we selected one diel cycle to represent the range of characteristics observed over $16 \mathrm{~d}$ of measurements. In the early spring (10 April), before canopy leaf emergence, there was a wide range of air temperatures, from $1^{\circ}$ at 0600 to $23^{\circ}$ at midday (Fig. 2A). The average leaf temperature was higher than the air temperature during the day from 0800 to $\approx 1500$, and the largest difference between the leaf and air temperatures $\left(4^{\circ}-8^{\circ}\right)$ was at midday (Fig. 2B). Leaf tem- 


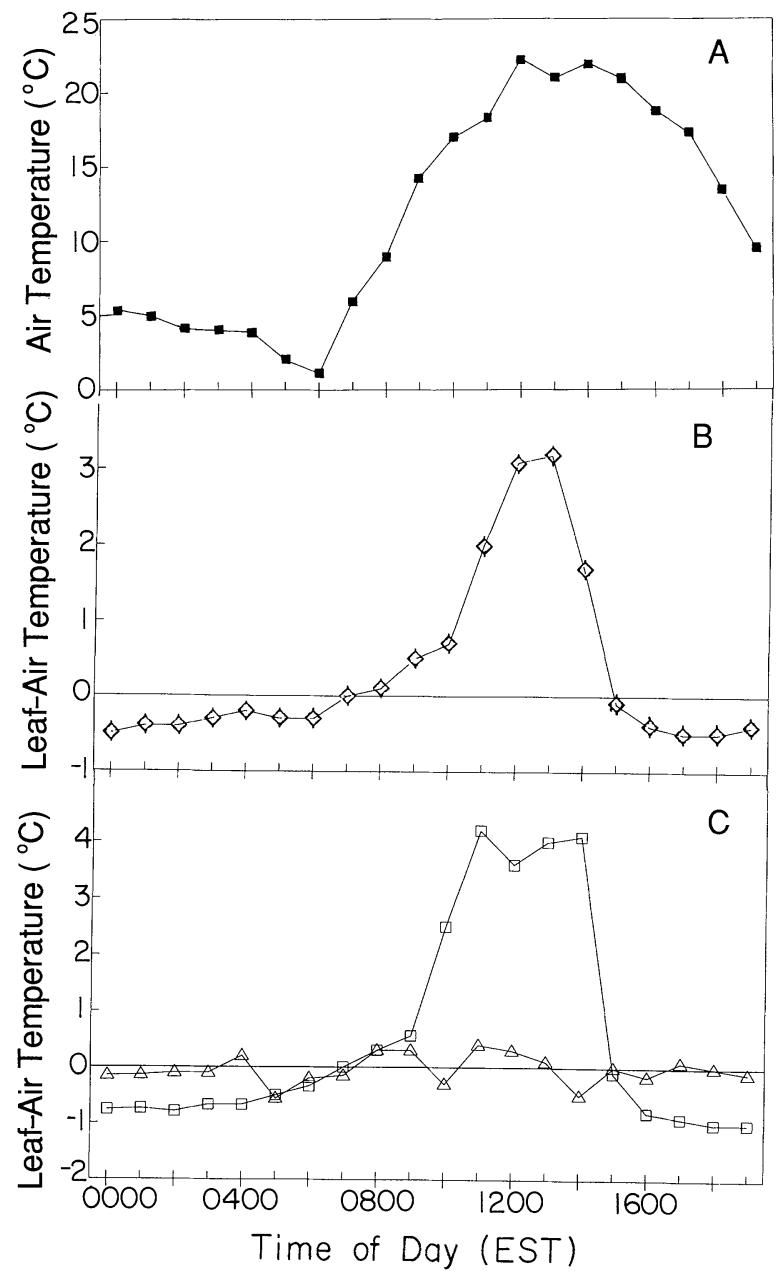

FIG. 2. Diel cycle of in situ leaf and air temperatures of Rhododendron maximum on 10 April, 1985. (A) Average air temperature. (B) Average difference between leaf and air temperatures. Sample size equals 12 (two in each of six treatments. (C) Average difference between leaf and air temperatures for in situ Rhododendron maximum leaves held in a vertical $(\triangle)$ or a horizontal $(\square)$ position. Sample size $=2$ for each category. EST $=$ Eastern Standard Time.

peratures were lower than air temperatures during the other hours of the day (1500-0800), but the difference was $<1^{\circ}$ for all treated groups (Fig. 2B).

The comparison of leaf temperatures among different groups revealed that the horizontal-treatment leaves had leaf temperatures higher than those of verticaltreatment leaves during the day (Fig. 2C). The verticalleaf temperature was close to air temperature (difference $\left\langle 1^{\circ}\right.$ ) during the entire day (Fig. 2C). On the other hand, the leaf temperature of horizontal leaves was lower than that of vertical leaves at night, and above that of all other treatments (up to $7^{\circ}$ ) during the day (Fig. 2C).

During midday (from 1200 to 1500 ), the variation in vertical-leaf temperature was $<2.5^{\circ}$ on a short-term basis (5-min interval). However, there were sharp temperature changes in horizontal leaves (Fig. 3A, B). Leaf temperature of horizontal leaves changed $5^{\circ}$ or more in one 5-min interval. The steep leaf-temperature increases were caused by sunflecks. This result indicated that the light environment was quite different between the horizontal and vertical leaves. That is, horizontal leaves received a greater quantum intensity during sunflecks than did vertical leaves. On the other hand, the different temporal patterns of temperature variation between the $H C$ (free to curl but restrained horizontal) and $H F$ (restrained flat and horizontal) leaves were due to the position of individual leaves within the variable pattern of sunflecks in the subcanopy.

\section{Photosynthetic relationships}

An examination of photosynthesis at a series of different temperatures was carried out to determine the optimal temperature for photosynthesis of Rhododendron maximum. We found optimal temperature of $30^{\circ}-$ $34^{\circ}$ (Fig 4). Rates of net photosynthesis rose steeply below the temperature optimum and declined more slowly above the optimal temperature. During the summer, average maximum air temperature at this site was $23^{\circ}$. Although $R$. maximum had a temperature optimum for photosynthesis $\geq 7^{\circ}$ higher than the av-

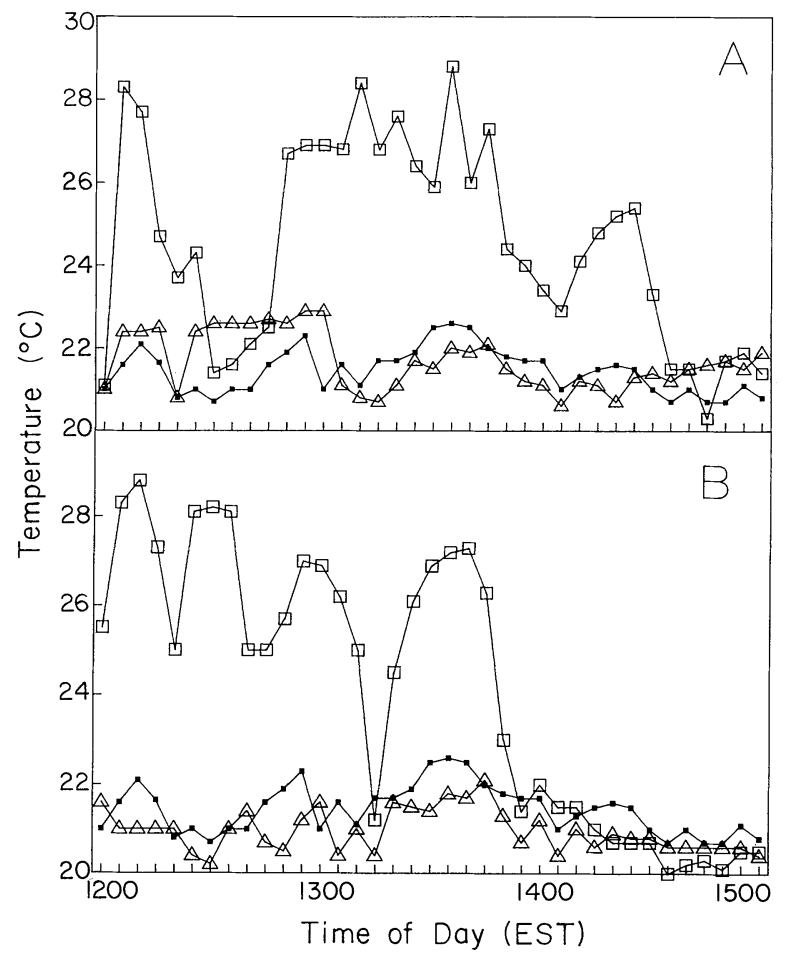

FIG. 3. In situ Rhododendron maximum leaf and air temperatures as measured at 5-min intervals by continuously recording thermocouples. $\square$ horizontal leaves; $\triangle$ vertical leaves; air temperature. (A) Leaves restrained flat. (B) Leaves allowed to curl. EST $=$ Eastern Standard Time. 
erage maximum air temperature, the temperatures of horizontal leaves (normal summer position) in sunflecks could rise only $5^{\circ}$ or $6^{\circ}$ above air temperature.

The measurements of light dependence of photosynthesis were carried out in July and August of 1986 in order to detect if permanent photoinhibition resulted from winter leaf treatments. Photosynthesis, as a function of light intensity at optimal temperature and ambient $\mathrm{CO}_{2}$ concentration, showed a linear response to photon flux density up to $160 \mu \mathrm{mol} \cdot \mathrm{m}^{-2} \cdot \mathrm{s}^{-1}$. Net photosynthesis saturated at photon flux density near 250 $\mu \mathrm{mol} \cdot \mathrm{m}^{-2} \cdot \mathrm{s}^{-1}$ (Fig. 5). However, there were substantial differences in light response curves among the groups. First, the average maximum photosynthetic rate of control leaves was significantly ( $t$ test, 95\% confidence level) higher than that of other groups (Table 1). The maximum photosynthetic rates of each of the other manipulated groups ranged from 1.03 to 1.33 $\mu \mathrm{mol} \cdot \mathrm{m}^{-2} \cdot \mathrm{s}^{-1}$, which were not significantly different from each other at the $95 \%$ confidence level (Table 1).

Similarly, leaf conductance was higher in the control leaves than in the manipulated leaves except for the flat and horizontal leaves. Intercellular $\mathrm{CO}_{2}$ concentration $\left(C_{i}\right)$ was not significantly different between the control and most manipulated leaves. Only treatment 6 (flat and horizontal) leaves had a significantly elevated $C_{i}$. The average water-use efficiency was the lowest in treatments 5 and 6 (the horizontal leaves).

Significant differences among treatments were found at low irradiances (Fig. 6). The control leaves (which had holes punched and the wire frame attached) had photosynthetic responses similar to those of unmanipulated leaves at low irradiances (Fig. 6). The horizontal leaves (treatment 5 and 6) had significantly lower photosynthesis at low irradiance than the control leaves. Photosynthesis of vertical leaves was variable and intermediate between that of the horizontal and of the control leaves. For example, at $100 \mu \mathrm{mol} \cdot \mathrm{m}^{-2} \cdot \mathrm{s}^{-1}$ incident irradiance, horizontal leaves had only $49.5 \%$ of control

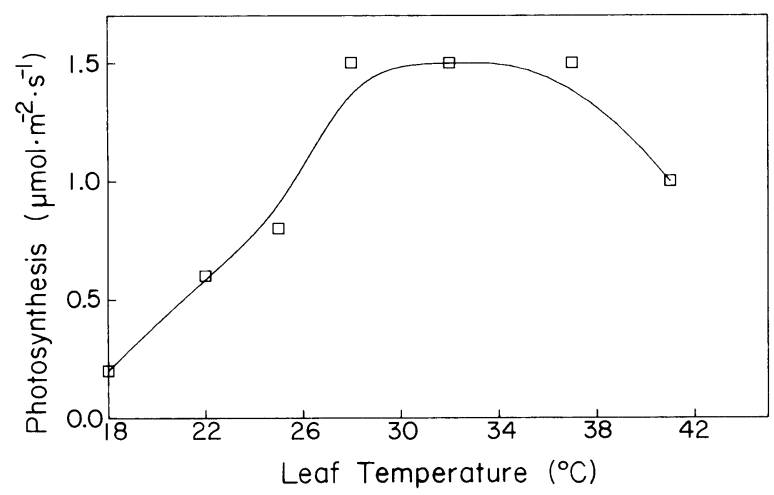

FIG. 4. A representative temperature response of net photosynthesis in Rhododendron maximum leaves under a deciduous canopy. (Leaf age $=2 \mathrm{yr} ; \operatorname{PAR}=700 \mu \mathrm{mol} \cdot \mathrm{m}^{2} \cdot \mathrm{s}^{-1}$; vapor pressure deficit $<1.0 \mathrm{kPa}$; leaf water potential $=-0.5$ $\mathrm{MPa} ;\left[\mathrm{CO}_{2}\right]=350 \mu \mathrm{mol} / \mathrm{mol} ;\left[\mathrm{O}_{2}\right]=21 \%$ ).

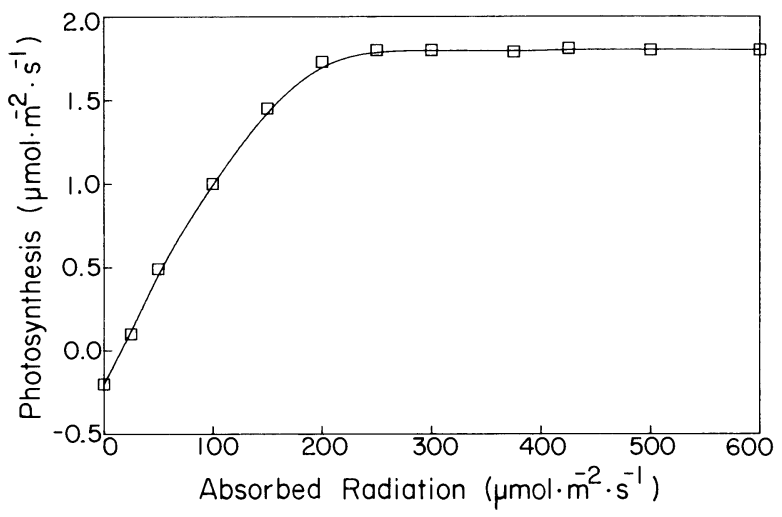

FIG. 5. A representative photosynthetic (net $\mathrm{CO}_{2}$ uptake) response to absorbed radiation in Rhododendron maximum leaves from under a deciduous canopy. (Leaf age $=2 \mathrm{yr}$; leaf temperature $=30^{\circ} \mathrm{C}$; vapor pressure deficit $<1.0 \mathrm{kPa}$; leaf water potential $=-0.75 \mathrm{MPa} ;\left[\mathrm{CO}_{2}\right]=350 \mu \mathrm{mol} / \mathrm{mol} ;\left[\mathrm{O}_{2}\right]$ $=21 \%$ ).

photosynthesis, while vertical leaves averaged $58.6 \%$ of the control photosynthetic rates.

Among the vertical and horizontal leaf treatments there was little difference between the photosynthetic low-light response of leaves in the flat and the curling treatments. The largest difference was found between the horizontal flat leaves (treatment 6) and the horizontal curled leaves (treatment 5), which was a difference of $<5 \%$, and not significant (Fig. 6).

The difference in photosynthesis at low irradiance among treatments reflected significant differences in quantum yield (slope of $\mathrm{CO}_{2}$ assimilation vs. irradiance at low irradiance). The average quantum $\mathrm{CO}_{2}$ assimilation yield of control leaves $(9.5 \mu \mathrm{mol} / \mathrm{mol}$ quanta) was significantly higher ( $t$ test, $95 \%$ confidence limits) than that of vertical $(8.0 \mu \mathrm{mol} / \mathrm{mol}$ quanta) leaves.

Chlorophyll contents were analyzed to indicate the possible occurrence of photooxidation as a result of the winter treatments. In previous studies we found that leaf chlorophyll contents naturally decrease after $2 \mathrm{yr}$ of age, but the chlorophyll content within each age cohort of leaves is uniform (Nilsen and Bao 1988). In accordance with these earlier data the chlorophyll concentrations of the six manipulations were not significantly different (Duncan's test, 95\% confidence limit) at the beginning of the experiment. Four months after treatment (May measurement) the chlorophyll contents of the horizontal leaves (treatments 5 and 6) were significantly lower than that of the control or vertical leaves (Fig. 7). No differences were found in the chlorophyll $a / b$ ratio among groups.

\section{Leaf mortality relationships}

The percentage of leaves surviving in each treatment was calculated on 10 April 1987. The survivorship of the control group was similar to that of unmanipulated leaves (Nilsen 1986), 96\% for age 2 leaves, and 54\% 


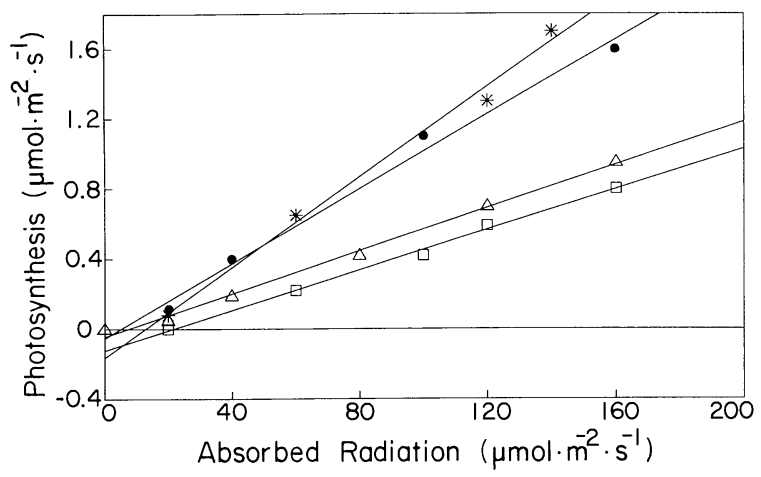

FIG. 6. Photosynthetic $\left(\mathrm{CO}_{2}\right.$ uptake) response of Rhododendron maximum leaves to low irradiance. $\left(\left[\mathrm{CO}_{2}\right]=350\right.$ $\mu \mathrm{mol} / \mathrm{mol}$; leaf temperature $=30^{\circ} \mathrm{C}$; vapor pressure deficit $<$ $1.0 \mathrm{kPa}$; leaf water potential $\left.=-0.75 \mathrm{MPa} ;\left[\mathrm{O}_{2}\right]=21 \%\right)$. * unmanipulated leaves; $\bullet$ control leaves; $\Delta$ vertical leaves; $\square$ horizontal leaves.

for age 3 leaves. The leaf survival of other treatments was lower than that of control leaves (Fig. 8). The difference between horizontal and vertical leaves was greater than that between the curling and no-curling groups. The leaf treatments were ranked in the following order from least to most mortality: CONT (treatment 1) $=$ Unmanipulated (treatment 7) $>F F($ treatment 4) $>H F($ treatment 6$)>H C$ (treatment 5) $>$ $V F($ treatment 3$)>V C($ treatment 2$)$.

\section{Discussion}

\section{Thermal significance}

The thermotropic leaf movements in Rhododendron maximum occur only during the winter months when temperatures are below $0^{\circ} \mathrm{C}$. During the summer months the leaves are continuously close to horizontal and uncurled. The traditional explanations of significances of

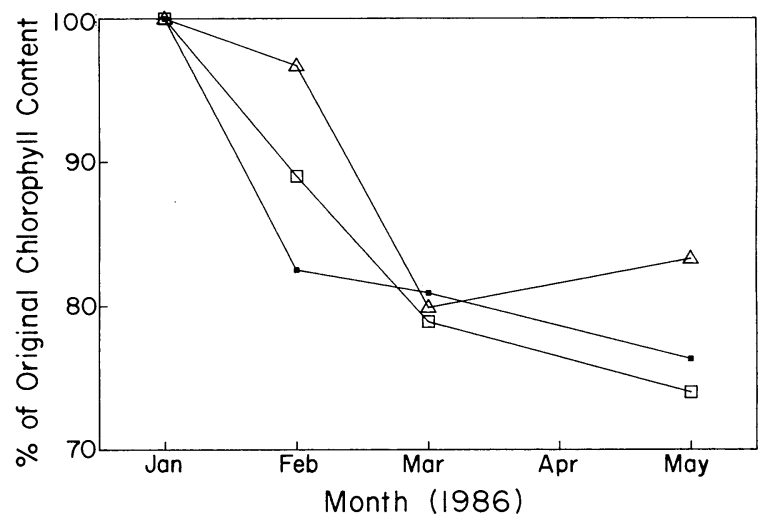

FIG. 7. Relative chlorophyll contents of 2-yr-old Rhododendron maximum leaves. Values on 12 February are taken as $100 \%$. control leaves; $\Delta$ vertical leaves; $\square$ horizontal leaves; $n=16$ leaves per treatment).

leaf movements have concerned avoidance of overheating during periods of drought and/or excessive irradiance (Mooney et al. 1977, Geller and Smith 1982, Forseth and Ehleringer 1983). But, thermotropic leaf movements of Rhododendron maximum occur during periods of low temperature and moderate moisture supply (Nilsen 1985, 1987). So there must be significances other than avoidance of foliar overheating to explain winter thermotropic leaf movements.

Thermotropic leaf movements may serve to reduce the effects of cellular freezing on cell physiology, particularly during cold nights when leaves have a strongly negative infrared balance. The adverse effects of low (chilling or freezing) temperatures on cell physiology have been reported in many species (Powles 1984). However, these effects are reduced in darkness even for cold-sensitive plants (Lasley et al. 1979, Van Hasselt and Van Berlo 1980, Powles et al. 1983). R. maximum is a low-temperature tolerant species, in which

TABLE 1. Photosynthetic characteristics of Rhododendron maximum leaves under a deciduous canopy in the southern Appalachian Mountains. Values reported are means \pm 1 standard error of the mean ( $n=6$ to 8 per treatment).

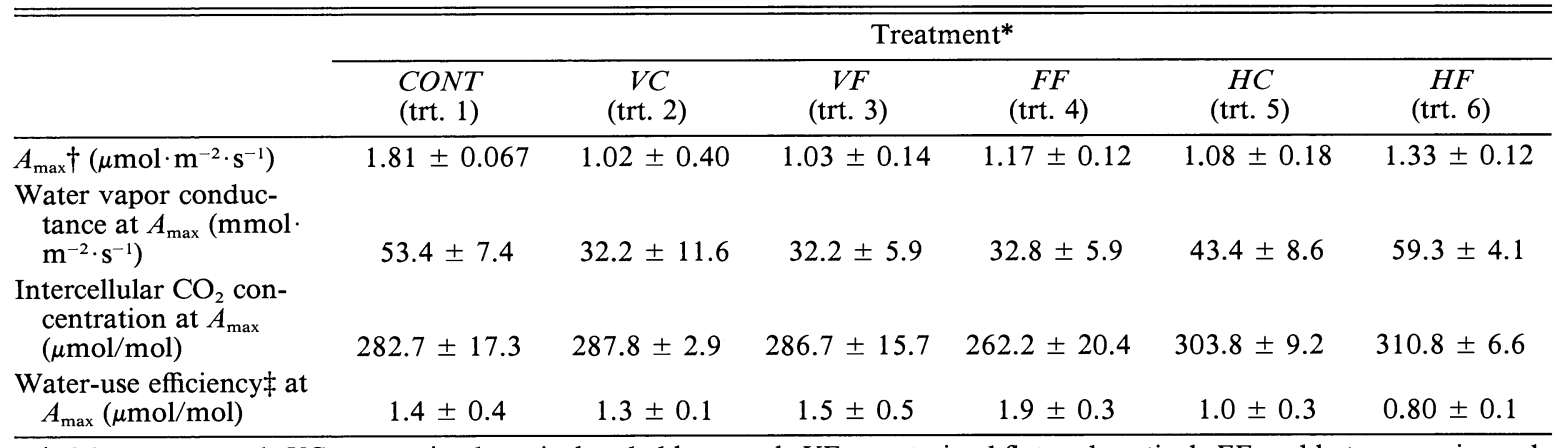

* CONT = control; $V C=$ restrained vertical and able to curl; $V F=$ restrained flat and vertical; $F F=$ able to move in angle but restrained flat; $H C=$ able to curl and restrained horizontal; $H F=$ restrained flat and horizontal.

$\dagger$ Maximum $\mathrm{CO}_{2}$ assimilation rate at a $\mathrm{CO}_{2}$ concentration of $350 \mu \mathrm{mol} / \mathrm{mol}$, leaf temperature $30^{\circ} \mathrm{C}, \mathrm{PAR} 300$ $\mu \mathrm{mol} \cdot \mathrm{m}^{-2} \cdot \mathrm{s}^{-1}$, and vapor pressure deficit $<1.0 \mathrm{kPa}$.

$\ddagger$ Net $\mathrm{CO}_{2}$ uptake per unit $\mathrm{H}_{2} \mathrm{O}$ flux. 
leaves withstand temperatures $15^{\circ}-20^{\circ}$ below the leaf freezing point $\left(-7^{\circ}\right)$ without any damage during the winter. Therefore, the difference in nocturnal temperature $\left(<1^{\circ}\right)$ between the horizontal and control leaves found in this study is not physiologically critical. In addition, previous studies (Nilsen 1986) demonstrated that leaf drooping occurs at $-1^{\circ}$, which is $5^{\circ}$ higher than the freezing point of $R$. maximum leaves. Based on the above observations, we feel that the leaf-drooping movements of $R$. maximum play only a minor role in avoiding potential freezing damage to cell physiology by ameliorating the infrared radiation balance.

It has been shown that the rate of temperature change is a critical factor associated with freezing damage (Levitt, 1980). The results of this study reveal that leaf temperatures could increase $5^{\circ}-7^{\circ}$ in a short period of time (within $5 \mathrm{~min}$ ) when leaves are exposed to sunflecks. Leaf movement could reduce the speed of leaf thaw by reducing the irradiance load, thereby avoiding potential damage by rapid thaw.

In subcanopy plants, sunflecks often play an important role in both leafenergy balance and photosyn thesis (Chazdon and Pearcy 1986). Sunflecks were frequent during the winter months of our study, at which time the horizontal leaves received a greater photon flux density than the vertical leaves. As a result, the horizontal leaves increased as much as $7^{\circ}$ over ambient air temperature. It is possible, as in many desert plants, that excessive solar absorption could cause increases in leaf temperature, potentially resulting in membrane damage. This is particularly critical for large leaves with high solar absorption coefficients such as $R$. $\max$ imum. However, during sunflecks the leaf temperature of horizontal leaves was still well below the optimum temperature for photosynthesis during the summer (Fig. 4) or the winter as found by Martinez (1975). Normally, overheating causes damage, as indicated by membrane leakage, at leaf temperatures well above the photosynthetic thermal optimum (Berry and Björkman 1980, Monson et al. 1982). Consequently, it is unlikely that thermotropic leaf movements prevent winter leaf damage caused by overheating.

\section{Photosynthetic significances}

Examining the effects of winter leaf treatments on subsequent spring and summer photosynthetic characteristics provided an alternative way to determine the ecological significances of thermotropic leaf movements. Our second hypothesis was that winter leaf movements prevented photoinhibition caused by low temperature and high irradiance. Photoinhibition induced by illumination of plants at low temperature can be due to the inhibition of electron transport, photophosphorylation, and enzyme activity (Powles 1984). Photoinhibition is frequently determined by either chlorophyll fluorescence or gas-exchange measurements. Gas-exchange measurements were conducted

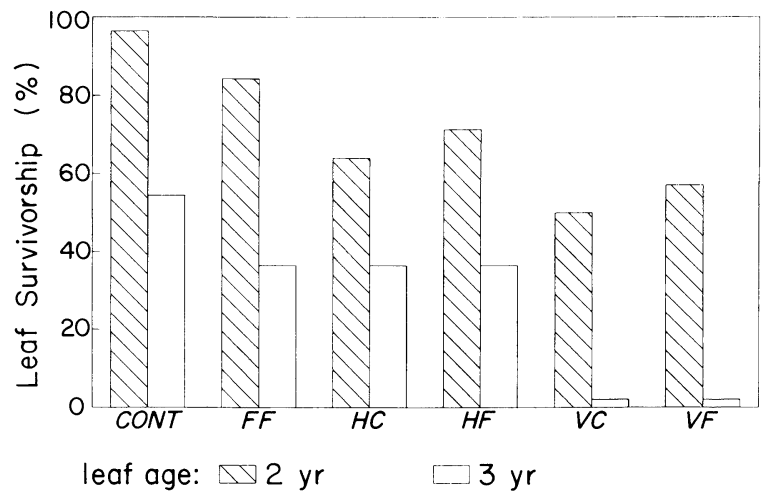

FIG. 8. Leaf survivorship of Rhododendron maximum leaves 1 yr after experimental treatments were imposed. CONT $=$ control; $F F=$ leaves restrained flat, but free to change angle; $H C=$ leaves restrained horizontal and allowed to curl; $H F=$ leaves restrained both horizontal and flat; $V C=$ leaves restrained vertical and allowed to curl; $V F=$ leaves restrained both vertical and flat.

after the leaf treatments were established for $1 \mathrm{yr}$, in order to detect permanent photoinhibition. The marked reduction in maximum photosynthesis of horizontal leaves compared with control leaves (Table 1) indicates the occurrence of photoinhibition, which may have been due to a reduction of enzyme activity or photochemical processes. The lower quantum yield of treated leaves suggests that the inhibition of electron transport capacity or light harvesting may also have been involved. It has been reported that shade plants have much lower electron transport capacities than sun plants (Björkman et al. 1972b, Boardman et al. 1972). $R$. maximum is a shade plant; therefore, photoinhibition could be induced by the absorption of excess excitation energy at the photosynthetic reaction center in the winter (higher light environment and low temperatures). Low intercellular oxygen partial pressure, because of the closed stomata, would increase this adverse effect.

Intercellular carbon dioxide concentrations $\left(C_{i}\right)$ are the result of the relationship between leaf conductance and photosynthesis. The trend toward higher $C_{i}$ in the immobile (in angle) leaves indicates a proportionately greater reduction in photosynthesis than conductance. Leaf conductance is strongly influenced by minor changes in leaf water potential of $R$. maximum (Lipscomb 1986). The higher $C_{i}$ of the horizontal leaves was paralleled by low water-use efficiency. Consequently, thermotropic leaf movements may be of particular importance to carbon balance during periods of low water availability in the next growing season.

\section{Carbon balance significance}

The plant carbon balance is a combined result of many factors such as respiration of nonphotosynthetic organs, net photosynthetic rates, and leaf area (Mooney 1972). Our manipulation study indicated that without winter thermotropic leaf movements net photosyn- 


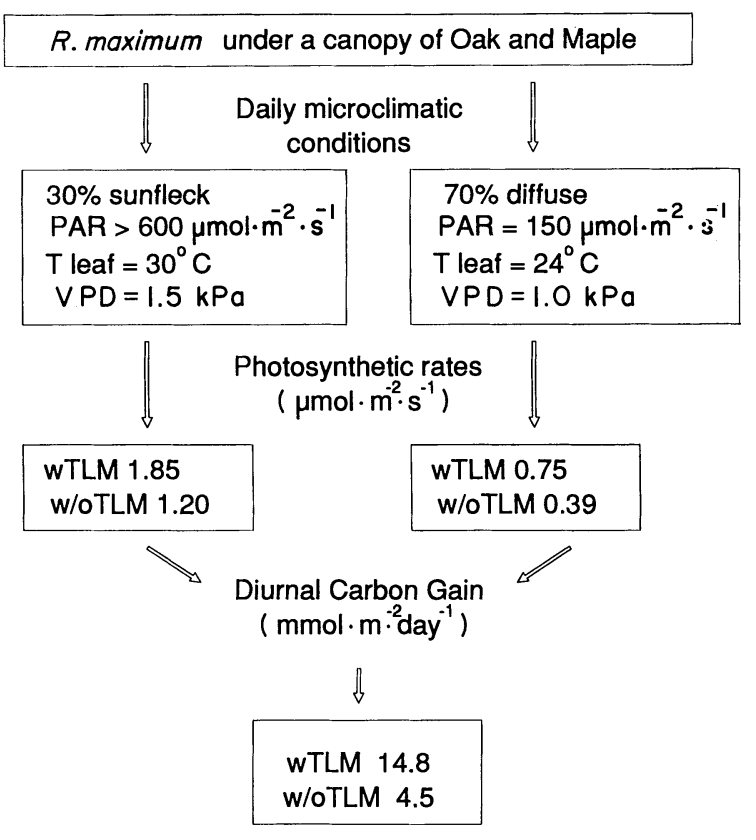

FIG. 9. A flow diagram representing the photosynthetic performance of horizontal leaves in the summer (July) after a winter period with thermotropic leaf movements (wTLM) or without thermotropic leaf movements (w/oTLM).

thetic rates would be reduced and leaf mortality would increase. The general environmental condition of this site and our photosynthetic and mortality data were used to calculate the carbon gain per square metre of leaf area and per leaf age cohort (Fig. 9). Our irradiance data indicated that the $R$. maximum leaves in this site were in sunflecks for $30 \%$ of the day and in diffuse radiation for $70 \%$ of the day. Average PAR during the sunflecks was $>600 \mu \mathrm{mol} \cdot \mathrm{m}^{-2} \cdot \mathrm{s}^{-1}$, while the diffuse radiation averaged $150 \mu \mathrm{mol} \cdot \mathrm{m}^{-2} \cdot \mathrm{s}^{-1}$. In sunflecks, leaves warmed to $6^{\circ}$ over air temperature, and average summer air temperature was $24^{\circ}$. Vapor pressure deficits were rarely below $1.5 \mathrm{kPa}$ (Nilsen 1985), which had little effect on photosynthetic performance of these leaves.

During sunflecks net photosynthesis $\left(P_{n}\right)$ averaged $1.85 \mu \mathrm{mol} \cdot \mathrm{m}^{-2} \cdot \mathrm{s}^{-1}$ if thermotropic leaf movements had occurred during the previous winter; but $P_{n}$ only achieved $1.20 \mu \mathrm{mol} \cdot \mathrm{m}^{-2} \cdot \mathrm{s}^{-1}$ if thermotropic leaf movements had not occurred. During diffuse radiation, the $P_{n}$ rates would be $0.75 \mathrm{ad} 0.39 \mu \mathrm{mol} \cdot \mathrm{m}^{-2} \cdot \mathrm{s}^{-1}$ with and without thermotropic leaf movements, respectively. These $P_{n}$ rates were calculated over a diurnal cycle in July for this latitude (taking into account $70 \%$ diffuse radiation) and resulted in a diurnal net carbon gain of $14.8 \mathrm{mmol} \cdot \mathrm{m}^{-2} \cdot \mathrm{d}^{-1}$ and $4.5 \mathrm{mmol} \cdot \mathrm{m}^{-2} \cdot \mathrm{d}^{-1}$ for leaves that had thermotropic leaf movements in comparisor: with those that did not have winter leaf movements. Thus, on a leaf-area basis, the absence of winter leaf movements could result in only $31 \%$ of the possible carbon gain (per unit leaf area) by leaves retaining thermotropic leaf movements.

When the influence of mortality is added, the cohort carbon gain is reduced to $20 \%$ of that possible by the cohort of leaves that retained thermotropic leaf movements. However, we investigated leaves that were 1 and $2 \mathrm{yr}$ old during the winter and 2 and $3 \mathrm{yr}$ old the following summer during our photosynthetic studies. At this site leaves have a longevity of $5 \mathrm{yr}$ (Nilsen 1986), and after $4 \mathrm{yr}$ photosynthetic performance is minimal (Nilsen et al. 1988). If we could have treated younger age classes of leaves, the overall significance of winter leaf movement may have been greater, because the 0 and $1 \mathrm{yr}$ age categories contribute a major part of the canopy carbon gain.

Longevity of leaves on $R$. maximum (Nilsen 1986) and the rates of photosynthetic decline with age (Nilsen et al. 1988) are site specific. In sites with very low irradiance, leaves are longer lived (Nilsen 1986), their chlorophyll contents are constant with increasing age (Nilsen and Bao 1988), and their photosynthetic rates are low but do not decline until 48 mo of age (Nilsen et al. 1988). The converse is true for high-light environments. We would then expect that thermotropic leaf movements would have different significances in different habitats because of the variation in winter irradiance and the compounding influence of repetitive winter conditions on the photosynthetic capacity of long-lived leaves. We have begun studies similar to this one on $0-1$ yr old leaves in a variety of subcanopy conditions.

\section{ACKNOWLEDGMENTS}

This research was supported by the VPI Small Project Grant (1896210), a grant from Sigma Xi, and the Virginia Academy of Sciences. Site-use permission was provided by the United States Forest Service, Blacksburg Office. Thanks to W. Winner and W. C. Johnson for comments on an earlier draft of this manuscript.

\section{Literature Cited}

Baskin, J. M., and C. C. Baskin. 1978. Leaf temperatures of Heliotropium tenellum and their ecological implication. American Midland Naturalist 100:488-492.

Berry, J. A., O. Björkman. 1980. Photosynthesis response and adaptation to temperature in higher plants. Annual Review of Plant Physiology 31:491-543.

Björkman, O., N. K. Boardman, J. M. Anderson, S. W. Thorne, D. J. Goodchild, and N. A. Pyliotish. 1972b. Effect of light intensity during growth of Atriplex patula on the capacity of photosynthetic reactions, chloroplast components and structure. Carnegie Institution of Washington Year Book 71:115-135.

Boardman, N. K., J. M. Anderson, S. E. Thorne, and O. Björkman. 1972. Photochemical reactions of chloroplasts and components of photosynthetic electron transport chain in two rainforest species. Carnegie Institution of Washington Year Book 71:107-114.

Chazdon, R. L., and R. W. Pearcy. 1986. Photosynthetic responses to light variation in rainforest species. I. Induction under constant and fluctuating light conditions. Oecologia (Berlin) 69:517-523.

Darwin, C. 1885. Pages 280-492 in The power of movement 
in plants. D. Appleton and Company, New York, New York, USA.

Field, C., J. A. Berry, and H. A. Mooney. 1982a. A portable system for measuring carbon dioxide and water vapor exchange of leaves. Plant Cell and Environment 5:179-186.

Field, C., N. Chiariello, and W. E. Williams. 1982b. Determinants of leaf temperature in California Mimulus species at different altitudes. Oecologia (Berlin) 55:414-420.

Forseth, I. N., and J. R. Ehleringer. 1982. Ecophysiology o two solar tracking desert winter annuals. I. Photosynthetic acclimation to growth temperature. Australian Journal of Plant Physiology 9:321-332.

Forseth, I. N., and J. R. Ehleringer. 1983. Ecophysiology of two solar tracking desert winter annuals. IV. Effects of leaf orientation on calculated daily carbon gain and water use efficiency. Oecologia (Berlin) 58:10-18.

Fukuda, Y. 1933. Hygronastic curling and uncurling movement of the leaves of Rhododendron micranthum Turcz. with respect to temperature and resistance to cold. Japanese Journal of Botany 6:191-224.

Gates, D. M. 1963. Leaf temperature and energy exchange. Archives Meteorology Geophysiks Sioklimatology Series B 12:321-336

1968. Transpiration and leaf temperature. Annual Review of Plant Physiology 19:211-238.

. 1980. Biophysical ecology. Springer-Verlag, New York, New York, USA.

Geller, G. N., and W. K. Smith. 1982. Influence of leaf orientation, and arrangement on temperature and transpiration in three high elevation large leafed herbs. Oecologia (Berlin) 53:227-234.

Havis, J. R. 1964. Why do rhododendron leaves curl. Horticulture 43:12.

Jeffrey, S. W., and G. F. Humphrey. 1975. New spectrophotometric equations for determining chlorophylls a,b,c, and $c_{2}$ in higher plants, algal, and natural phytoplankton. Biochemie und Physiologie der Pflanzen 167:191-194.

Lasley, S. E., M. P. Garber, and C. F. Hodges. 1979. Aftereffects of light and chilling temperatures on photosynthesis in excised cucumber cotyledons. Journal of the American Society for Horticultural Science 104:477-480.

Levitt, J. 1980. Responses of plants to environmental stress. Volume I. Academic Press, New York, New York, USA

Lipscomb, M. V. 1986. The influence of water and light on the physiology and spatial distributions of three shrubs in the southern Appalachian Mountains. Thesis. Virginia Polytechnic Institute and State University, Blacksburg, Virginia, USA.

Long, S. P., T. M. East, and N. R. Baker. 1983. Chilling damage to photosynthesis in Zea mays. I. Effects of light and temperature variation on photosynthetic assimilation. Journal of Experimental Botany 34:177-188.

Martinez, J. A. 1975. Seasonal trends in $\mathrm{CO}_{2}$ exchange in two evergreen shrubs in the eastern deciduous forest. Thesis. University of Georgia, Athens, Georgia, USA.

McMillen, G. G., and J. M. McClendon. 1979. Leaf angle: an adaptive feature of sun and shade leaves. Botanical Gazette 140:437-442.

Monson, R. K., M. A. Stidham, G. J. Williams III, G. E. Edwards, and E. G. Uribe. 1982. Temperature dependence of photosynthesis in Agropyron smithii Rydb. I. Factors affecting net $\mathrm{CO}_{2}$ uptake in intact leaves and contribution from ribulose-1,5-bisphosphate carboxylase measured in vivo and in vitro. Plant Physiology 69:921928.
Mooney, H. A. 1972. The carbon balance of plants. Annual Review of Ecology and Systematics 3:315-346.

Mooney, H. A., and J. R. Ehleringer. 1978. The carbon gain benefits of solar tracking in a desert annual. Plant Cell and Environment 1:307-311.

Mooney, H. A., J. R. Ehleringer, and O. Björkman. 1977. The energy balance of leaves of the evergreen shrub Atriplex hymenolytra. Oecologia (Berlin) 29:301-310.

Nilsen, E. T. 1985. Seasonal and diurnal leaf movements of Rhododendron maximum L. in contrasting irradiance environments. Oecologia (Berlin) 65:296-302.

. 1986. Quantitative phenology and leaf survivorship of Rhododendron maximum $\mathrm{L}$. in contrasting irradiance environments of the Southern Appalachian Mountains. American Journal of Botany 73:822-831.

$\rightarrow 1987$. Influence of water relations and temperature on leaf movements of Rhododendron species. Plant Physiology 83:607-612.

Nilsen, E. T., and Y. Bao. 1988. The influence of leaf age, season, and microclimate on the photosynthetic apparatus of Rhododendron maximum. I. Chlorophylls. Photosynthetica 21:535-542.

Nilsen, E. T., D. A. Stetler, and C. Gassman. 1988. The influence of leaf age, season, and microclimate on the photosynthetic apparatus of Rhododendron maximum. II. Chloroplasts and photosynthetic light response. American Journal Botany, in press.

Nobel, P. S. 1983. Pages 368-369 in Biophysical plant physiology and ecology. W. H. Freeman, San Francisco, California, USA.

Ogren, E. and G. Öquist. 1984. Photoinhibition of photosynthesis in Lemna gibba as induced by the interaction between light and temperature. II. Photosynthetic electron transport. Physiologia Plantarum 61:193-200.

Parkhurst, D. F., P. R. Duncan, D. M. Gates, and F. Kreith. 1968. Wind tunnel modeling of convection of heat between air and broad leaves of plants. Agricultural Meteorology 5: $33-47$.

Powles, S. B. 1984. Photoinhibition of photosynthesis induced by visible light. Annual Review of Plant Physiology 35:15-44.

Powles, S. B., J. A. Berry, and O. Björkman. 1983. Interaction between light and chilling temperature on the inhibition of photosynthesis in chilling sensitive plants. Plant Cell and Environment 6:117-123.

Regehr, D. L., and F. A. Bazzaz. 1976. Low temperature photosynthesis in successional winter annuals. Ecology 57: 1297-1303.

SAS. 1982. SAS user's guide: statistics. 1982 edition. SAS Institute, Cary, North Carolina, USA.

Smith, W. K. 1978. Temperature of desert plants: another perspective on the adaptability of leaf size. Science 201 : 614-616.

Strand, R. J., and G. Öquist. 1985. Inhibition of photosynthesis by freezing temperatures and high levels in cold acclimated seedlings of Scots pine Pinus sylvestris. I. Effects on the light-limited and light-saturated rates of $\mathrm{CO}_{2}$ assimilation. Physiologia Plantarum 64:425-430.

Van Hasselt, Ph.R., and H. A. C. Van Berlo. 1980. Photooxidative damage to the photosynthetic apparatus during chilling. Physiologia Plantarum 50:51-56.

Wallace, L. L., P. Timpano, and P. Durgin. 1987. Leaf folding in Mimosa pudica (Fabaceae) a nutrient conservation mechanism? American Journal of Botany 74:132-135. 